\title{
Caryological and physiological characteristics of rare species Potentilla porphyrantha Juz. (Rosaceae) in Armenia
}

\author{
Karine Janjughazyan* \\ Institute of Botany after A. Takhtadjan, NAS RA, Acharyan str. 1, Yerevan, 0040, Armenia
}

\begin{abstract}
Caryological and physiological features of rare species Potentilla porphyrantha Juz. were investigated. It was shown that this species is diploid with $2 \mathrm{n}=14(\mathrm{x}=7)$. Physiological investigation included study of water regime, intensity of transpiration and photosynthesis. It was shown, that this species growing in-situ conditions on Amulsar Mountain (2900 m a.s.l.) now is very good adapted to ex-situ conditions in the Sevan botanical garden (1900 m a.s.1.). It grows very well, bloom and produce viable seeds, and in the future could be reintroduced into nature.
\end{abstract}

\section{Introduction}

Potentilla porphyrantha Juz .(Rosaceae) has a very nare area of distribution growing only in Armenia, Nakhichevan and NW Iran. It is included in the Red Book of plants of Armenia in the category Critically Endangered [1]. N. Khanjyan [2] considered that in the flora of Armenia two very close species are existed - Potentilla porphyrantha and P.cryptophila. However, our special taxonomic studies [3] established that in Armenia we have only one of these species - P.porphyrantha, which probably grows in Zuvand as well. P.cryptophila doesn't grow in Armenia. Potentilla porphyrantha Juz. is a small, very ornamental plant with pink petals with red-purple base and veins, growing on bare rock outcrops on mountain peaks and ridges around $3000 \mathrm{~m}$ above sea level. In 2012 new rather big population of P.porphyrantha was found on the Amulsar mountain. A new rather big gold mine had to be established on this mountain, and big part of the population of $P$. porphyrantha could be destroyed. In this regard, we have undertaken a detailed study of this species, the main purpose of which is to study the possibilities of its conservation in exsitu conditions with further reintroduction into nature. For this purpose, about 2,000 plant specimens were transferred from the Amulsar mountain to the Sevan and Yerevan Botanical Gardens. We carry out taxonomic, bio-ecological, palynological, karyological, physiological studies of this species. All this will allow to assess the adaptive potential and develop effective methods for the conservation and return of this species to nature. In this article, we present the results of the investigation of the main physiological parameters (water regime, including free and bound water and water deficiency, and the intensity of

*Corresponding autor: kar2035@mail.ru 
transpiration and photosynthesis) of Potentilla porphyrantha, studied in in-situ and ex-situ conditions. As well we present the results of the karyological research.

\section{Materials and Methods}

Studies were conducted in the period 2015-2018 on Potentilla porphyrantha plants collected on Amulsar mountain at an altitude of 2900 m a.s.l. and grown in Sevan (1900 m a.s.l.) and Yerevan (1250 m a.s.l.) botanical gardens (Fig. 1). Climatic diagrams of these sites are presented in the fig. 2. At the same time, our research has shown that in the Sevan Botanical Garden, transplanted plants have successfully adapted to new conditions, abundantly bloom and bear seeds. In the Yerevan Botanical Garden, the plants, although bloom, but suffer from high summer temperatures, interrupt vegetation and gradually die.
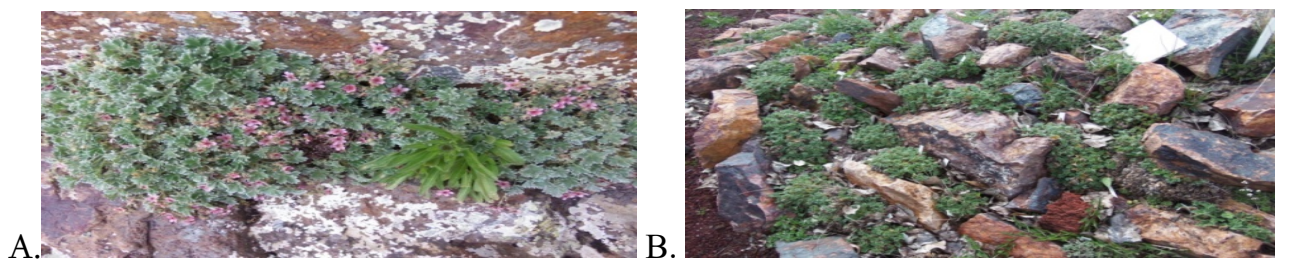

Fig. 1. Potentilla porphyrantha: A - in-situ (Amulsar Mountain) and B - ex-situ (Sevan Botanical garden) conditions.
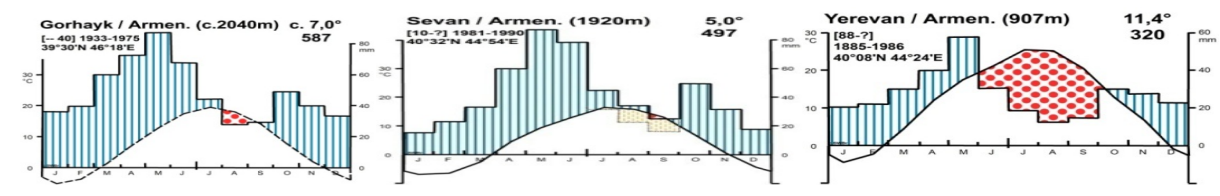

Fig. 2. Climatic diagrammes of Amulsar mountain (in situ) and Sevan and Yerevan botanical gardens (ex situ).

The caryological investigations were based on specimens collected during expeditions from Amulsar mountain. Investigations were made on the mitotic metaphases of the meristematic cells from root tips. The root tips were pretreated in $0,4 \%$ colchicines solution for 2 hours; fixed in fluid 1:1 alcohol and glacial acetic acid for at least 2 hours at room temperature. After hydrolysis in $\mathrm{HCl} 1 \mathrm{~N}$ for $10-15$ minutes at $60^{\circ} \mathrm{C}$ the root tips were stained in Schiff reagent at 1,5 hours. Then the root tips were squashed on a glass slide with $45 \%$ acetic acid. For all chromosome counts, a minimum of 10 plates were examined for each taxon. Chromosome types were established according A. Levan \& al. (1964) in the modification of N. D. Agapova and V. D. Grif [4].

Physiological studies were carried out according to the generally accepted methodology [5], and the results were subjected to statistical processing. All measurements were carried out in one period of time (11.00-13.00) in the early summer vegetation season, in three replications.

\section{Results and Discussion}

As result of caryological investigations we have found that it has diploid cytotype $(2 n=14)$ with basic number $\mathrm{x}=7$ (Fig. 3). 
Fig. 3. Karyotype of Potentilla porphyrantha $(2 \mathrm{n}=14)$.

Karyotype is simmetric (fig. 3) with very small metacentric chromosomes. The size of chromosomes varies from 0.76 to $1.54 \mathrm{mkm}$. TF Index $=49.67 \%$, karyotype's formula $2 \mathrm{n}=$ $14 \mathrm{M}$, and length of all chromosomes is $\sum=13.85 \mathrm{mkm}$.

In the most investigations devoted to the study of eco-physiological characteristics of plants, special attention is usually paid to the peculiarities of the water regime, because water availability and the state of water primarily determine the physiological activity of plants and their adaptability in various growing conditions [6]. Not less important for assessing the physiological activity and the success of plant adaptation to new growing conditions are indicators of the intensity of transpiration and photosynthesis. Table 1 shows the average parameters of the studied plants in different growing conditions.

Table 1. Water regime and transpiration and photosynthesis intensity of Potentilla porphyrantha in different growing conditions.

\begin{tabular}{|l|c|c|c|c|c|c|c|}
\hline $\begin{array}{c}\text { Locality and } \\
\text { elevation } \\
\text { (m a.s.l.) }\end{array}$ & $\begin{array}{c}\text { Water } \\
\text { content, } \\
\text { \% }\end{array}$ & $\begin{array}{c}\text { Free } \\
\text { water, \% }\end{array}$ & $\begin{array}{c}\text { Bound } \\
\text { water, \% }\end{array}$ & $\begin{array}{c}\text { Ratio of } \\
\text { free and } \\
\text { bound } \\
\text { water }\end{array}$ & $\begin{array}{c}\text { Water } \\
\text { deficit, } \\
\%\end{array}$ & $\begin{array}{c}\text { Transpiration } \\
\text { rate }\end{array}$ & $\begin{array}{c}\text { Photosynthesis } \\
\text { rate }\end{array}$ \\
\hline $\begin{array}{l}\text { Amulsar } \\
\text { Mountaine, } \\
2900 \mathrm{~m}\end{array}$ & 75,12 & 51,34 & 23,78 & 2,1 & 14,15 & 387,09 & 3,67 \\
\hline $\begin{array}{l}\text { Sevan } \\
\text { Botanical } \\
\text { garden, 1900 } \\
\text { m }\end{array}$ & 69,89 & 40,94 & 28,95 & 1,4 & 21,19 & 433,12 & 3,05 \\
\hline $\begin{array}{l}\text { Yerevan } \\
\text { Botanical } \\
\text { garden,1250 } \\
\text { m }\end{array}$ & 67,55 & 37,77 & 29,78 & 1,2 & 24,31 & 419,41 & 2,16 \\
\hline
\end{tabular}

Investigations of changes in indicators of the water regime depending on the altitude were conducted by numerous researchers in different mountain systems, in particular, on Aragats in Armenia [7, 8], in the Pamir [9], in Georgia on the Lesser Caucasus [10] and others. The data obtained as a result of these studies quite well coincide with our data on Potentilla porphyrantha. So, despite the fact that plants in the Yerevan and Sevan Botanical Gardens were grown under conditions of artificial irrigation, plants from natural habitat on Amulsar Mountain were characterized by higher rates of water regime and photosynthesis intensity. Indicators of water deficit and intensity of transpiration showed an inverse pattern, with increasing altitude of the area, the values of these indicators decreased.A similar dependence was noted for many plant species studied in the alpine belt of Mount Aragats and in the Yerevan Botanical Garden - the difference in the absolute altitude of the area is $2050 \mathrm{~m}$ [11]. The relationship of transpiration intensity with elevation should obviously be sought in the complex both in differences in edaphic, climatic and weather conditions (including changes in light intensity, atmospheric humidity, atmospheric pressure, temperature), and in structural changes of the plants themselves (the number and density of stomata on the leaves, the diffusion permeability of the leaves, etc.) [12]. In any case, both changes in the structural elements of plants and their functional changes should 
be considered as a complex of adaptation to climatic changes in the broad sense, aimed at maintaining homeostasis and dynamic equilibrium of plants [13].

\section{Conclusion}

As a result of our research, it can be stated that when we transfer plants of Potentilla porphyrantha from alpine to the meadow-steppe and semi-desert belts, they decrease the total and free water content and photosynthesis intensity, while increasing the bound water content, water deficiency and intensity of transpiration. Naturally, these changes indicate that plants tolerate stress from changes in growing conditions, and the magnitude of stress directly depends on the increase in the difference between the elevation of in-situ and exsitu conditions. However, both the general behavior of plants and relatively small changes in the physiological indices of plants grown under the conditions of the Sevan Botanical Garden suggest that stress is relatively small and the plants are fairly well adapted to the new growing conditions. A different picture is obtained when examining plants in the Yerevan Botanical Garden - here the stress and changes in physiological parameters turn out to be much greater, which leads first to the oppression of the plants, and then to their death.It can be concluded that, specifically for the Potentilla porphyrantha species, the conditions of the Sevan Botanical Garden are relatively favorable, and the garden itself can be used to conserve, reproduce and grow this species, with subsequent reintroduction into nature in future.

\section{References}

1. K. Tamanyan, G. Fayvush, S. Nanagyulyan, T. Danielyan (eds.). The Red Data Book of Plants of Armenia (Zangak, Erevan, 2010)

2. N. S. Khandjyan, Flora, vegetation and plant resources of Armenia, 17 (2009)

3. M. Oganesian, K. Janjughazyan, Takhtadjania, 4 (2018)

4. N. D.Agapova, V.D. Grif, Bot. Journ., 67, 9 (1982)

5. A. I. Salnikov, I. L. Maslov, Physiology and bio-chemistry of plants: practice (Izd-vo FGBOU VPO Permskaya GSKHA, Perm', 2014)

6. N. A. Gusev, Water condition in plants (Nauka, Moscow, 1974)

7. A. G. Gasparyan, Some morpho-physiological peculiarities of alpine plants grows on different altitudes: PhD thesis (Yerevan, 1966)

8. R. K. Simonyan Bio-physiological variability of some high mountains plants growing in different conditions on Aragats mountain: PhD thesis (Yerevan, 1999).

9. V. M. Sveshnikova, Proc. Int. symp. Ecology of high mountains (Tbilisi, 1988)

10. Sh. Sikharulidze, Proc. Int. symp. Ecology of high mountains (Tbilisi, 1988)

11. A. G.Gasparyan, Proc. of Inst. of Botany NAS RA, 20 (Yerevan, 1977)

12. M. Sanchez, F. Petroni, A. Oliveira-Filho, Changes in forest with altitude in the Brazilian Coastal Atlantic rain Forest, in Abstracts of the XVI Lutern. Bot. Congress, St. Louis, USA (1999)

13. W. Larkher, Peculiarities of water regime of some alpine plants, Climatic stress and plants behavior in high mountains, in Proc. Int. symp. Ecology of high mountains, Tbilisi (1988) 